PRZEGLĄD RUSYCYSTYCZNY 2021, nr 2 (174)

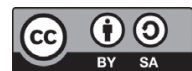

DOI 10.31261/pr.10085

\author{
АНАСТАСИЯ УРЖА \\ Московский государственный университет имени М.В. Ломоносова \\ (iD http://orcid.org/0000-0001-9506-977X
}

\title{
ЛОКАЛИЗАЦИЯ ДЕЙКТИЧЕСКОГО ЦЕНТРА НАРРАТИВА В РУССКИХ ПЕРЕВОДАХ АНГЛОЯЗЫЧНОЙ ПРОЗЫ (XIX-ХХІ ВВ.)
}

\begin{abstract}
LOCALIZATION OF DEICTIC NARRATIVE CENTRE
IN RUSSIAN TRANSLATIONS OF PROSE IN ENGLISH (19TH-21ST CENTURIES)

The research is focused on the means of localizing the deictic center of a narrative in Russian translations of prose in English. Comparative analysis of translated variants and originals shows the approximating trend (widespread, but not universal) in Russian texts, marked by inserting proximal deictic words like 'today', 'here', 'now' in the passages concerning past events, employing historic present instead of past tense forms. These changes are usually made within the segments of narrative with internal focalization. The approximation is influenced by specific features of Russian grammar system (there are no strict rules for sequence of tenses, no constructions with Complex Object etc.) and by different narrative tradition (historical present is not so marked stylistically, and more widespread). Making the deictic center closer to the readers in Russian translations is often connected with the translator's strategy highlighting author's devices for internal focalization in a narrative. Keywords: deixis, deictic centre, focalisation, Russian translated narrative
\end{abstract}

Дейктический центр повествования, то есть позиция, с которой в определенный момент рассматриваются и подаются события сюжета ${ }^{1}$, традиционно связывается с тремя координатами: темпоральной, пространственной и персональной. Нарративный дейксис, называемый также вторичным ${ }^{2}$, отсылает не к условиям и участникам речевого акта, а к произвольно выбранному моменту и месту событий нарратива, которые можно представить в воображении (deixis ad phantasma, по Карлу Бюлеру3). Чаще всего в фокусе исследований оказываются вре-

1 S. C. Levinson, Pragmatics, CUP, Cambridge 1983, c. 64.

2 Ю. Д. Апресян, Избранные труды. Интегральное описание языка и системная лексикография, т. II, Школа «Языки русской культуры», Москва 1995, c. 632.

3 K. Bühler, Sprachtheorie. Die Darstellungsfunktion der Sprache, Gustav Fischer, 
менное и пространственное измерения нарративного дейксиса, возможности приближать детали повествуемых событий (например: В 1820 году Пушкин отправляется на военном бриге в Гурзуф и здесь пишет элегию Погасло дневное светило) или отдалять их (например: Тогда у Толстого не было возможности быстро переслать рукопись издателю). Однако и персональное измерение, характеризующее дейктический центр, заслуживает пристального внимания. Во-первых, выбор ракурса изложения событий обусловлен предпочтением точки зрения определенного текстового субъекта - фокального персонажа или повествователя. По воле автора тот или иной герой может в определенный момент оказаться владельцем «кинокамеры», транслирующей восприятие описываемых явлений, а «передача» кинокамеры другому модусному субъекту сопровождается сдвигом дейктического центра - значимым изменением нарративной перспективы ${ }^{4}$. Во-вторых, есть еще одно «заинтересованное лицо» в этом процессе - все приемы приближения или отдаления событий сюжета при помощи дейктических отсылок ориентированы на читателя, именно он оказывается зрителем транслируемых картин, и каждый сдвиг дейктического центра привлекает его внимание, требуя усилий в работе воображения, конструирующего художественный хронотоп. Не случайно нарративный дейксис определяют как «интерактивную» характеристику повествования 5 .

Различаются ли принципы локализации дейктического центра в нарративах на разных языках? Какие факторы влияют на использование дейктических показателей в переводных текстах? Недавно пришедшие на службу лингвистическому анализу корпусные методы исследования могут помочь изучить это вопрос комплексно. Цель данной статьи - представить результаты изучения поведения дейктиков на материале параллельных текстов, составляющих поливариантный набор русских переводов англоязычных художественных произведений $\mathrm{XIX-XX} \mathrm{вв.} \mathrm{(ряд} \mathrm{переводов} \mathrm{выполнен} \mathrm{и} \mathrm{в} \mathrm{XXI} \mathrm{в.).} \mathrm{Исследование}$

Jena 1934.

4 E. M. Segal, Narrative comprehension and the role of Deictic Shift Theory // J.F. Duchan, G.A. Bruder, L.E. Hewitt (eds.), Deixis in Narrative: a Cognitive Science Perspective, Lawrence Erlbaum, Hillsdale, New Jersey 1995, c. 3-18.

5 I. Mason, A. Şerban, Deixis as an Interactive Feature in Literary Translations from Romanian into English, "Target" 2004, № 15 (2), c. 269-294. 
опирается как на данные текстов, включенных в параллельный подкорпус Национального корпуса русского языка, так и на дополнительные источники, собранные и обработанные автором статьи.

В начале XXI века было проведено несколько сопоставительных корпусных исследований дейктических элементов в переводных текстах. Ян Мейсон и Адриана Шербан сравнили в румынских оригинальных нарративах и их англоязычных переводах количество приближающих ("proximals”) и дистанцирующих (“distals”) дейктиков. Объектами анализа стали слова 'now' - 'then', 'here' - 'there', 'this'-'that', 'these'-'those' и под., а также формы настоящего исторического и прошедшего нарративного времени. Результатом стала констатация дистанцирующей тенденции при переводе с румынского на английский язык: в выбранных учеными типовых фрагментах из 11 текстов была обнаружена устойчивая тенденция к замене приближающих дейктических элементов на дистанцирующие ('this' на 'that', 'now' на 'then', настоящее историческое на прошедшее нарративное и т.п.), опущению приближающих и добавлению дистанцирующих элементов. Авторы подчеркнули, что все обнаруженные замены не обусловлены расхождением языковых систем, переводчик в каждом случае мог сделать и другой выбор, но предпочел именно это решение. Обнаруженная тенденция охватывает все изученные переводы. По мнению Яна Мейсона и Адрианы Шербан, она связана с особенностями интерпретации нарратива при переводе с румынского на английский. Ученые считают, что предпочтение дистанцирующих элементов может быть связано с их большей распространенностью, немаркированностью в англоязычной повествовательной традиции ${ }^{6}$. Обратившись к голландским нарративам и их переводам на испанский язык, Патрик Гуталс и Джули Де Вилде отметили, что этот материал не демонстрирует явной тенденции к дистанцированию (или напротив, приближению) точки зрения на события. Закономерности в этой области были выявлены только в рамках отдельных произведений. Авторы выдвинули гипотезу о том, что важным фактором приближения/дистанцирования дейктического центра может стать манера переводчика, его «про-

6 Там же, с. 274. 
чтение» оригинала, обусловленное спецификой перспективы произведения7.

Материалом нашего сопоставительного анализа стали 22 англоязычных прозаических произведения и 107 их русских переводов, выполненных на протяжении последнего столетия. Исследование проводилось с опорой на данные словарей и справочников времени создания оригиналов и переводов. Для разностороннего изучения дейктиков в выбранных текстах мы комбинировали эвристический и дедуктивный методы: количественные подсчеты позволили сформулировать первые гипотезы, а лингвостилистический анализ расширенных контекстов с учетом типа повествования и особенностей перспективы нарратива дал возможность уточнить наблюдения и детализировать выводы.

Рассмотрим основные тенденции в употреблении дейктиков на примере слов 'today' и 'сегодня', а затем расширим круг анализируемых средств. По утверждению Елены Падучевой, 'сегодня’ - первичный, или «жесткий», эгоцентрик, при изменении режима интерпретации (с речевого на гипотаксический или нарративный), он меняет референцию, отсылая к актуальной временной позиции говорящего ${ }^{8}$ (ср.: Позавчера Петя сказал: «Сегодня не пойду в школу». Позавчера Петя сказал, что сегодня не пойдет в школу). Употребление 'сегодня' без изменения референции возможно в рамках свободного косвенного дискурca, например: Петя выбежал из дома. Что же ему теперь делать? Нет, в школу он сегодня ни за что не пойдет.

Значения наречий 'today' и 'сегодня', зафиксированные в словарях, не изменились за период, охватывающий время создания изучаемых переводов (написание 'to-day' постепенно заменилось на 'today'), и между русским и английским словом нетрудно установить соотношение (в отличие от случаев более сложной корреляции слов 'now' - 'сейчас', 'теперь', 'нынче' и др.; 'here' 'здесь', 'тут', 'сюда' и др.).

Приведем примеры количественного соотношения употребления слов 'today' и 'сегодня' в ряде объемных текстов, доступных для подсчетов (см. таблицу 1).

7 P. Goethals, J. De Wilde, Deictic Center Shifts in Literary Translation: the Spanish Translation of Nooteboom's Het Volgende Verhaal, «Meta» 2009, № 54 (4), c. $770-794$.

8 Е.В. Падучева, Эгоцентрические единицы языка, Издательский Дом ЯСК, Москва 2019, с. 48. 
Таблица 1. Использование слов ‘today’ и ‘сегодня’ в англоязычных нарративах и их русскоязычных переводах.

\begin{tabular}{|c|c|c|c|c|c|}
\hline произведение & today & перевод & сегодня & перевод & сегодня \\
\hline $\begin{array}{l}\text { О. Уайльд } \\
\text { Портрет } \\
\text { Дориана Грэя }\end{array}$ & 13 & $\begin{array}{l}\text { Перевод } \\
\text { М. Абкиной }\end{array}$ & 77 & $\begin{array}{l}\text { Перевод } \\
\text { В. Чухно }\end{array}$ & 81 \\
\hline $\begin{array}{l}\text { А. Конан } \\
\text { Дойл Собака } \\
\text { Баскервилей }\end{array}$ & 12 & $\begin{array}{l}\text { Перевод Е. } \\
\text { Ломиковской }\end{array}$ & 46 & $\begin{array}{l}\text { Перевод Н. } \\
\text { Волжиной }\end{array}$ & 31 \\
\hline $\begin{array}{l}\text { П.Л. Трэверс } \\
\text { Мэри } \\
\text { Поппинс }\end{array}$ & 15 & $\begin{array}{l}\text { Перевод } \\
\text { М. Литвиновой }\end{array}$ & 55 & $\begin{array}{l}\text { Перевод } \\
\text { И. Родина }\end{array}$ & 48 \\
\hline $\begin{array}{l}\text { П.Г. Вудхауз } \\
\text { Этот } \\
\text { неподража- } \\
\text { емый Дживз }\end{array}$ & 7 & $\begin{array}{l}\text { Перевод } \\
\text { А. Балясникова }\end{array}$ & 59 & $\begin{array}{l}\text { Перевод } \\
\text { М. Гилинского }\end{array}$ & 44 \\
\hline $\begin{array}{l}\text { Ч. Буковски } \\
\text { Почтамт }\end{array}$ & 15 & $\begin{array}{l}\text { Перевод } \\
\text { М. Немцова }\end{array}$ & 20 & $\begin{array}{l}\text { Перевод } \\
\text { Ю. Медведько }\end{array}$ & 20 \\
\hline $\begin{array}{l}\text { Р. Брэдбери } \\
451^{\circ} \text { по } \\
\text { Фаренгейту }\end{array}$ & 10 & $\begin{array}{l}\text { Перевод } \\
\text { Т. Шинкарь }\end{array}$ & 34 & $\begin{array}{l}\text { Перевод } \\
\text { В. Бабенко }\end{array}$ & 35 \\
\hline $\begin{array}{l}\text { К.С. Льюис } \\
\text { Хроники } \\
\text { Нарнии }\end{array}$ & 29 & $\begin{array}{l}\text { Перевод } \\
\text { Г. Островской }\end{array}$ & 51 & $\begin{array}{l}\text { Перевод } \\
\text { В. Воседого, } \\
\text { В. Волковского, } \\
\text { Д. Афиногенова }\end{array}$ & 53 \\
\hline
\end{tabular}

Безусловно, частота употребления слова 'сегодня' зависит от содержания произведения, а также от его жанровых особенностей (например, от наличия эпистолярных или дневниковых вкраплений в нарратив), поэтому количество соответствующих слов в оригиналах различается, однако в русских переводах разных произведений заметно более активное использование этого первичного эгоцентрика, чем в исходных текстах.

Обнаруженное явление ставит перед нами ряд вопросов: заменяет ли слово 'сегодня' другие элементы оригинального текста или добавляется переводчиками? Наблюдаются ли такие изменения в прямой речи персонажей или собственно в нарративе?

Обратимся к детальному анализу русских переводов двух произведений из вышеперечисленного списка, представляющих соответственно третьеличное и перволичное повествование. 
Первая книга Памелы Линдон Трэверс о Мэри Поппинс представлена на русском языке в двух переводах (Марины Литвиновой и Игоря Родина), а также в пересказе Бориса Заходера, очень близком к переводу, однако имеющем ряд композиционных изменений 9 .

Количество слов 'today'/сегодня', использованных в прямой речи и в тексте повествователя, в оригинале, переводах и пересказе таково (см. таблицу 2):

Таблица 2. Использование слов 'today' и 'сегодня' в оригинале, переводах и пересказе повести П. Л. Трэверс Мэри Поппинс

\begin{tabular}{|c|c|c|c|c|c|c|c|}
\hline \multicolumn{2}{|c|}{} & \multicolumn{2}{|c|}{$\begin{array}{c}\text { Пер. } \\
\text { М. Литвиновой }\end{array}$} & \multicolumn{2}{c|}{$\begin{array}{c}\text { Пер. } \\
\text { И. Родина }\end{array}$} & \multicolumn{2}{c|}{$\begin{array}{c}\text { Пересказ } \\
\text { Б. Заходера } \\
\text { (количесто глав } \\
\text { сокращено) }\end{array}$} \\
\hline пр. речь & $\begin{array}{c}\text { нарра- } \\
\text { тив }\end{array}$ & пр. речь & $\begin{array}{c}\text { нарра- } \\
\text { тив }\end{array}$ & пр. речь & $\begin{array}{c}\text { нарра- } \\
\text { тив }\end{array}$ & пр. речь & $\begin{array}{c}\text { нарра- } \\
\text { тив }\end{array}$ \\
\hline 14 & 1 & 46 & 9 & 38 & 10 & 23 & 2 \\
\hline
\end{tabular}

Видно, что слово 'сегодня' в русских переводах более активно используется и в диалогах, и в нарративе. Какие факторы на это влияют? Рассмотрим примеры введения слова 'сегодня', не коррелирующего с 'today', в рамках третьеличного повествов ан и я:

В первую очередь, слово 'сегодня' добавляется переводчиками в нарратив в тех случаях, когда в тексте представлена точка зрения персонажа ${ }^{10}$.

\begin{tabular}{|l|l|l|l|}
\hline P.L. Travers & $\begin{array}{l}\text { Пер. } \\
\text { М. Литвиновой }\end{array}$ & Пер. И. Родина & $\begin{array}{l}\text { Пересказ } \\
\text { Б. Заходера }\end{array}$ \\
\hline $\begin{array}{l}\text { 1a. And indeed, } \\
\text { his heart felt heavy } \\
\text { with the thought } \\
\text { that something, he }\end{array}$ & $\begin{array}{l}\text { Сердце его } \\
\text { сжималось от } \\
\text { тревожного } \\
\text { предчувствия: }\end{array}$ & $\begin{array}{l}\text { На сердце у него было } \\
\text { тяжело, странное } \\
\text { предчувствие, что вот- } \\
\text { вот что-то должно }\end{array}$ & $\begin{array}{l}\text { Ему было } \\
\text { действительно } \\
\text { не по себе. Он } \\
\text { чувствовал: что-то } \\
\text { должно }\end{array}$ \\
\hline
\end{tabular}

9 А. В. Уржа, Перцептивизация как элемент переводческой тактики, «Гуманитарный вектор» 2014, № 4 (40), с. 57-62.

${ }^{10} \mathrm{~B}$ англоязычном нарративе нет запрета на такой прием, однако он встречается реже, чем в русских текстах, в повести П.Л. Трэверс - единожды: "Michael thought of school, and that one day he would have to go there. But even that seemed funny today and he had to laugh". 


\begin{tabular}{|l|l|l|l|}
\hline $\begin{array}{l}\text { did not quite know } \\
\text { what, was about to } \\
\text { happen at Number } \\
\text { Seventeen, Cherry } \\
\text { Tree Lane. }\end{array}$ & $\begin{array}{l}\text { что-то сегодня } \\
\text { должно случиться } \\
\text { в доме N 17 по } \\
\text { Вишневой улице. }\end{array}$ & $\begin{array}{l}\text { стрястись в доме № 17 } \\
\text { по Вишневой улице, } \\
\text { не покидало его ни на } \\
\text { минуту. }\end{array}$ & $\begin{array}{l}\text { случиться в Доме } \\
\text { Номер Семнадцать } \\
\text { по Вишнёвому } \\
\text { переулку. }\end{array}$ \\
\hline $\begin{array}{l}\text { 1b. But Jane wasn't } \\
\text { listening. She was } \\
\text { thinking about all } \\
\text { that had happened, } \\
\text { and wondering... }\end{array}$ & $\begin{array}{l}\text { Но Джейн не } \\
\text { слышала. Она } \\
\text { погрузилась } \\
\text { в размышления }- \\
\text { что же у них в доме } \\
\text { произошло? }\end{array}$ & $\begin{array}{l}\text { Но Джейн не } \\
\text { слышала. Она } \\
\text { думала обо всем, что } \\
\text { произошло сегодня, } \\
\text { и видела сны... }\end{array}$ & $\begin{array}{l}\text { Но Джейн его не } \\
\text { слышала. Она } \\
\text { что пробовошешло, } \\
\text { и о том, что ещё } \\
\text { теперь будет... }\end{array}$ \\
\hline
\end{tabular}

В представленных фрагментах эксплицировано введение внутренней фокализации (с помощью слов 'thought', 'wondering', 'knew'), однако переводчики дополняют этот прием, задействуя дейктик 'сегодня' (М. Литвинова и И. Родин) или 'теперь' (Б. Заходер), а также пользуясь отсутствием в русском языке необходимости согласования времен при передаче размышлений персонажа, имевших место в прошлом («что-то должно случиться», «что произошло сегодня», «что еще теперь будет»). Таким образом, в действие вступают сразу два фактора: индивидуальные переводческие решения «накладываются» на особенности грамматики языка (важно подчеркнуть, что переводчики могли обойтись без добавления соответствующих дейктиков, и такие варианты также представлены в таблице).

В ряде случаев 'сегодня' при переводе заменяет дистанцирующий показатель 'that day', 'that afternoon', приближая дейктический центр повествования к читателю (см. варианты И. Родина и Б. Заходера):

\begin{tabular}{|c|c|c|c|}
\hline P.L. Travers & $\begin{array}{l}\text { Пер. } \\
\text { М. Литвиновой }\end{array}$ & Пер. И. Родина & \begin{tabular}{|l} 
Пересказ \\
Б. Заходера
\end{tabular} \\
\hline $\begin{array}{l}\text { 2a. Sometimes he } \\
\text { would give some to } \\
\text { Jane and Michael } \\
\text { for their money- } \\
\text { boxes, and when he } \\
\text { couldn't spare any } \\
\text { he would say, «The } \\
\text { Bank is broken,» and } \\
\text { they would know he } \\
\text { hadn't made much } \\
\text { money that day. }\end{array}$ & $\begin{array}{l}\text { Иногда он давал } \\
\text { детям монетки, } \\
\text { а они бросали } \\
\text { их в копилки. } \\
\text { Но случалось, } \\
\text { что монеток } \\
\text { не было, и он } \\
\text { говорил: «Банк на } \\
\text { ремонте», - и все } \\
\text { понимали, что } \\
\text { в тот день он } \\
\text { вырезал совсем } \\
\text { мало денег. }\end{array}$ & $\begin{array}{l}\text { Время от времени } \\
\text { кое-что перепадало } \\
\text { и Джейн с Майклом } \\
\text { для их копилок. Но } \\
\text { иногда мистер Бэнкс } \\
\text { возвращался с пустым } \\
\text { портфелем. В таких } \\
\text { случаях он говорил: } \\
\text { «Банк лопнул»,- } \\
\text { и дети сразу понимали, } \\
\text { что сегодня ничего не } \\
\text { получат. }\end{array}$ & $\begin{array}{l}\text { Иногда он давал } \\
\text { монетку-другую } \\
\text { Джейн и Майклу } \\
\text { (в копилку), а уж } \\
\text { если он не мог, то } \\
\text { говорил: «Банк } \\
\text { лопнул», и ребята } \\
\text { понимали, что } \\
\text { ничего не попишешь } \\
\text { - значит, папа } \\
\text { сегодня сделал } \\
\text { слишком мало } \\
\text { денег. }\end{array}$ \\
\hline
\end{tabular}


2b. And yet, strange to say, during that afternoon Mary Poppins never said a cross word.

Весь день Мэри
Поппинс ни разу
не рассердилась.
Правда, она
за весь день
и двух слов не
произнесла.

А Мэри Поппинс и впрямь вела себя сегодня очень странно. За весь день она не сказала никому ни единого сердитого слова.
А между тем, как

ни странно, за весь этот день

Мэри Поппинс не сказала ни единого сердитого слова.

Слово 'сегодня' в нарративе привлекает внимание читающего, дополнительно актуализируя для него описываемую ситуацию, предлагая ему разделить впечатления от нее с героем модусным субъектом.

Каждый из приведенных выше примеров может представляться единичным частным случаем, однако в комплексе 18 вставок в третьеличном нарративе слова 'сегодня' в трех русскоязычных версиях повести на фоне единственного употребления в оригинале демонстрируют тенденцию к приближению дейктического центра повествования к читателю, дополнительной субъективизации текста.

В диалогах повести таких вставок обнаружено еще больше (см. таблицу 2), однако и причины, и эффекты подобных изменений иные. В прямой речи мы имеем дело с имитацией речевого режима употребления эгоцентриков, точкой отсчета для использования дейктиков является момент и место речи говорящих персонажей, поэтому при добавлении слова 'сегодня' уже нельзя говорить о приближении к нам дейктического центра нарратива - скорее мы наблюдаем дополнительную отсылку к времени диалога, сопровождающуюся большей конкретизацией, чем в оригинале. В ряде случаев такое добавление - результат свободной интерпретации фрагмента текста переводчиком (таких примеров больше обнаруживается у Литвиновой), например:

\begin{tabular}{|l|l|l|}
\hline P.L. Travers & Пер. М. Литвиновой & Пер. И. Родина \\
\hline 3. «And I wish & - Хорошо бы & - Н-да, хотелось бы мне, чтобы \\
Robertson Ay would & и Робертсон Эй ушел & вот так же, ни слова не говоря, \\
go without a word of & без предупреждения. & и Робертсон Эй ушел куда- \\
warning, for he has & Он опять почистил & нибудь Он опять почистил \\
again polished one & один ботинок. & только один ботинок, а ко \\
boot and left the other & Согласись, вид у & второму даже не притронулся. \\
untouched. I shall look & меня сегодня слегка & Из-за него я снова буду \\
very lopsided.» & кособокий. & выглдеть кособоким! \\
\hline
\end{tabular}


В других ситуациях мы имеем дело с различиями на уровне типичных языковых номинаций: английские 'this time', 'this morning', регулярно заменяются на 'сегодня', 'сегодня утром' (хотя и вариант 'этим утром' тоже появляется), 'tonight' переводится как 'сегодня' или 'сегодня вечером', а фраза "It is my birthday” ожидаемо интерпретируется как "Сегодня мой день рождения». Таким образом, языковой и стилистический факторы употребления дейктиков в прямой речи, где активно используются клише, становятся более заметными, но и индивидуальные переводческие решения (такие, как в приведенном выше примере) обуславливают значительный процент замен (например, у Литвиновой это 25\% от всех случаев использования слова ‘сегодня' в диалогах). Опущение дейктика 'today' при переводе было обнаружено всего один раз и только в прямой речи - в переводе Родина.

Перейдем к анализу контекстов со словом 'сегодня' в перволичном повествовании. Этот неподражаемый Дживс Пелама Гренвилла Вудхауза - произведение, оформленное как воспоминания главного героя о недавно происшедших событиях и включающее немало диалогов. Количество слов 'today' / 'сегодня’, использованных в прямой речи и в тексте повествователя, в оригинале и переводах таково (см. таблицу 3):

Таблица 3. Использование слов 'today' и ‘сегодня' в оригинале и переводах романа П.Г. Вудхауза Этот неподражаемый Дживс

\begin{tabular}{|c|c|c|c|c|c|}
\hline \multicolumn{2}{|c|}{ оригинал } & \multicolumn{2}{c|}{ Пер. А. Балясникова } & \multicolumn{2}{c|}{ Пер. М. Гилинского } \\
\hline пр.речь & нарратив & пр.речь & нарратив & пр.речь & нарратив \\
\hline 7 & о & 57 & 2 & 39 & 5 \\
\hline
\end{tabular}

В зоне нарратива слово 'today' в оригинале не используется ни разу, в русских переводах возникает семь раз. Приведем несколько контекстов:

\begin{tabular}{|c|c|c|}
\hline P.G. Wodehouse & Пер. А. Балясникова & Пер. М. Гилинского \\
\hline $\begin{array}{l}\text { 4a. Well, we gazed at one } \\
\text { another for a bit [...] and } \\
\text { then I tore myself away. But } \\
\text { before I went I had been } \\
\text { booked up to take brother } \\
\text { and girl for a nice drive that } \\
\text { afternoon. }\end{array}$ & $\begin{array}{l}\text { Мы вдоволь попялились } \\
\text { друг на дружку [...] } \\
\text { и я слинял. Но перед этим } \\
\text { вынужден был пообещать } \\
\text { после обеда прокатиться } \\
\text { на автомобиле вместе } \\
\text { с девицей и ее братцем. }\end{array}$ & $\begin{array}{l}\text { Ну вот, мы осмотрели друг } \\
\text { друга [...] и я откланялся. } \\
\text { Но прежде чем я ушёл, мне } \\
\text { было велено развлечь брата } \\
\text { с сестрой автомобильной } \\
\text { прогулкой сегодня днём. }\end{array}$ \\
\hline
\end{tabular}


4b. He opened the door, and in popped Aline Hemmingway and her brother. The last persons I had expected. I really had thought that I could be alone for a minute in my own room.

\begin{tabular}{|l|l|} 
Он отворил дверь, & Он открыл дверь, \\
и я увидел Алин Хемингуэй & и в комнату впорхнули мисс \\
и ее брата. Этого еще & Хемингуэй и её братец. По \\
не хватало! Я искренне & правде говоря, я совсем \\
надеялся, что заслужил на & не ожидал их увидеть. Уж \\
сегодня право на отдых. & по крайней мере в моём \\
& номере они могли бы \\
& оставить меня в покое. \\
\hline
\end{tabular}

В первом примере мы видим замену дистанцирующего показателя 'that afternoon' на приближающий, во втором слово 'сегодня’ добавляется в текст, представляя ситуацию так, как будто рассказчик мысленно воображает себя, свои эмоции и впечатления в тот самый день, когда происходили описываемые события. Сходный прием, хоть и гораздо реже, используется и в оригинальном тексте: в повествовании о прошлом трижды возникают приближающие указатели типа 'this moment'. Следовательно, можно говорить о том, что переводчики усиливают, акцентируют авторскую манеру, пользуясь возможностями русской нарративной традиции, причем Михаил Гилинский делает это немного чаще, чем Алексей Балясников.

Если же обратиться к прямой речи героев, то здесь в обоих переводах подавляющее количество (92\%) случаев употребления слова 'сегодня' соотносится с номинациями 'this morning' или 'tonight' и не представляет смещения дейктического центра, реализуя закономерное соответствие номинаций в двух языках. В остальных ситуациях дейктик действительно добавляется, однако он не изменяет, а актуализирует временную отсылку к моменту речи персонажей, например:

\begin{tabular}{|c|c|c|}
\hline P.G. Wodehouse & Пер. А. Балясникова & Пер. М. Гилинского \\
\hline $\begin{array}{l}\text { 5. 'Jeeves,' I said firmly, } \\
\text { 'my mind is made up. } \\
\text { I am feeling a little } \\
\text { low-spirited and need } \\
\text { cheering. }\end{array}$ & $\begin{array}{l}\text { - Дживс, - твердо сказал я. - } \\
\text { Я так решил. У меня сегодня } \\
\text { тоскливо на душе, мне нужно } \\
\text { взбодриться. }\end{array}$ & $\begin{array}{l}\text { - Дживз, - твёрдо } \\
\text { сказал я. - Моё } \\
\text { решение окончательно } \\
\text { и бесповоротно. У меня } \\
\text { плохое настроение, } \\
\text { и я должен его исправить. }\end{array}$ \\
\hline
\end{tabular}

Опущение слова 'today' встречается в переводах романа о Дживзе всего два раза и только в контексте диалога.

Итак, использование дейктика 'сегодня' в проанализированных текстах различается в зоне собственно нарратива и в прямой речи персонажей. Явления, обнаруженные в зоне наррати- 
ва, представляют для нас наибольший интерес. В третьеличном повествовании слово 'сегодня' периодически добавляется переводчиками, способствуя дополнительной субъективизации и приближению дейктического центра текста к читателю. В перволичном нарративе, представляющем воспоминания героя о прошедших событиях, вставка слова 'сегодня' также способствует воображаемому приближению описываемой ситуации. В прямой же речи героев, введенной в тексты как от первого, так и от третьего лица, закономерности использования дейктика 'сегодня' иные: в большинстве случаев речь идет о языковой трансформации популярных англоязычных дейктиков типа 'this morning'; действительные вставки слова 'сегодня’ представляют переводческую инициативу и не смещают, а актуализируют, дополнительно подчеркивают отсылку ко времени диалога.

Аналогичные закономерности обнаруживаются при изучении поведения других дейктиков в переводах. Тенденция к приближению дейктического центра сопровождает повествование о прошлом в русских интерпретациях. Она реализуется не у всех переводчиков, поэтому можно говорить о значимости индивидуальных решений, которые в ряде случаев усиливают авторские приемы, а иногда продиктованы стремлением выделить определенное событие в тексте. Однако многочисленность таких явлений в переводах разных произведений побуждает нас выдвинуть гипотезу о предрасположенности русской переводческой нарративной традиции к более активному приближению дейктического центра повествования к читателю в рамках внутренней фока л и з а ц и (то есть в тех фрагментах текста, где представлена точка зрения персонажа), см. примеры из переводов различных произведений:

\begin{tabular}{|c|c|}
\hline \multicolumn{2}{|c|}{ ПОВЕСТВОВАНИЕ ОТ ТРЕТЬЕГО ЛИЦА } \\
\hline R. Bradbury Fahrenheit 451 & Пер. Т. Шинкарь \\
\hline $\begin{array}{l}\text { 6a. He did not wish to open the curtains } \\
\text { and open the french windows, for he did } \\
\text { not want the moon to come into the room. }\end{array}$ & $\begin{array}{l}\text { Однако он не поднял штор и не открыл } \\
\text { балконной двери - он не хотел, чтобы } \\
\text { сюда заглянула луна. }\end{array}$ \\
\hline C.S. Lewis The Chronicles of Narnia & Пер. Г. Островской \\
\hline $\begin{array}{l}\text { 6b. But Tirian could not understand why } \\
\text { there were so many of them: nor why they } \\
\text { were cutting down a Narnian forest. }\end{array}$ & $\begin{array}{l}\text { Но Тириан не мог понять, откуда их здесь } \\
\text { так много и почему они рубят лес в Нарнии. }\end{array}$ \\
\hline
\end{tabular}




\begin{tabular}{|c|c|}
\hline \multicolumn{2}{|c|}{ ПОВЕСТВОВАНИЕ ОТ ПЕРВОГО ЛИЦА } \\
\hline A. Conan Doyle The Hound of Baskervilles & Пер. Н. Волжиной \\
\hline $\begin{array}{l}\text { 6c. The dark paneling glowed like bronze } \\
\text { in the golden rays, and it was hard to } \\
\text { realize that this was indeed the chamber } \\
\text { which had struck such a gloom into our } \\
\text { souls upon the evening before. }\end{array}$ & $\begin{array}{l}\text { Темная дубовая обшивка отливала бронзой } \\
\text { в золотых лучах, и теперь нам трудно } \\
\text { было представить, что всего лишь накануне } \\
\text { вечером эта комната навевала на нас такое } \\
\text { уныние. }\end{array}$ \\
\hline Ch. Bukowski The Post Office & Пер. М. Немцова \\
\hline $\begin{array}{l}\text { 6d. Again I was on a new route. [...] It was } \\
\text { an average residential neighborhood. No } \\
\text { apartment houses. Just house after house } \\
\text { with well-kept lawns. But it was a new } \\
\text { route and I walked along wondering where } \\
\text { the trap was. Even the weather was nice. }\end{array}$ & $\begin{array}{l}\text { Опять я попал на новый маршрут. [...] } \\
\text { Средний жилой район. Многоквартирных } \\
\text { зданий нет. Просто один дом за другим, } \\
\text { с ухоженными лужайками. Но это был } \\
\text { новый маршрут, и я ходил и думал: где же } \\
\text { тут ловушка? Даже погода стояла хорошая. }\end{array}$ \\
\hline
\end{tabular}

Приближение дейктического центра повествования также обеспечивается за счет введения переводчиками форм настоящего исторического вместо прошедшего нарративного. Введение форм презенса в рассказе о событиях прошлого нередко сопровождает «сдвиг» дейктического центра - переключение с внешней точки зрения повествователя на внутреннюю точку зрения персонажа.

Сопоставление русскоязычной и англоязычной нарративных традиций на протяжении последнего столетия позволяет выявить различия в подходах к использованию настоящего времени в повествовании о прошлом. Еще в начале XX века в классическом английском нарративе использование форм презенса считалось настолько сильным, ярким средством выделения, что авторам рекомендовали воздерживаться от его чрезмерного использования: «The historical present is one of the boldest of figures and, as is the case with all figures, its overuse makes a style cheap and ridiculous ${ }^{11}$. В русской литературе того времени такого ограничения не существовало. Приведем яркий пример: известный рассказ Антона Чехова Шуточка, написанный почти полностью в настоящем историческом, был дважды переведен на английский язык в начале XX века, и обе переводчицы: и Мэриан Фелл (1915), и Констанс Гарнетт (1922) - заменили презенс на формы прошедшего времени, ср.: «Я сажаю ее, бледную, дрожащую, в санки, обхватываю рукой и вместе с нею низвергаюсь

${ }^{11}$ J. F. Royster, S. Thompson, Guide to Composition, Scott, Foresman and Co, Chicago 1919. «Настоящее историческое - это самый 'жирный шрифт', и, как в случае с любым выделением, его чрезмерное использование делает стиль повествования вульгарным и смешным» (перевод мой - А.У.). 
в бездну...» (А.П.Чехов) - "I seated her, all pale and trembling, in the little sled, put my arm around her, and together we plunged into the abyss" (перевод М. Фелл).

В русских же переводах настоящее время при передаче повествования о прошлом активно использовалось уже несколько столетий:

Редкому и несистемному использованию настоящего исторического в переводах древнейшего времени противостоит регулярная эксплуатация этой формы начиная с XIV в. Изменение переводческой стратегии в отношении настоящего исторического, изначально связанное со стремлением к большей формальной точности в передаче оригинала, проходит путь к употреблению этого средства как осознанного переводческого приема ${ }^{12}$.

В проанализированном нами материале замены форм прошедшего времени на настоящее регистрируются и в гипотаксическом режиме, где они обусловлены языковыми факторами отсутствием в русской грамматике правила согласования времен и конструкций типа Complex Object (cм. примеры 7а и 7b), и в нарративном режиме, где переводчик самостоятельно задействует соответствующий прием (см. пример 7с, а также 1a, 2a, 6b):

\begin{tabular}{|c|c|}
\hline \multicolumn{2}{|c|}{ ПОВЕСТВОВАНИЕ ОТ ТРЕТЬЕГО ЛИЦА } \\
\hline O. Wilde The Nightingale and the Rose & Пер. М. Ликиардопуло \\
\hline $\begin{array}{l}\text { 7a. The Student looked up from the } \\
\text { grass, and listened, but he could not } \\
\text { understand what the Nightingale was } \\
\text { saying to him. }\end{array}$ & $\begin{array}{l}\text { Студент поднял голову с травы, } \\
\text { прислушался, но не мог понять, что ему } \\
\text { говорит Соловей. }\end{array}$ \\
\hline P.L. Travers Mary Poppins & Пер. Б. Заходера \\
\hline $\begin{array}{l}7 \text { b. Presently they saw their Mother } \\
\text { coming out of the drawing-room with } \\
\text { a visitor following her. Jane and Michael } \\
\text { could see that the newcomer had shiny } \\
\text { black hair- «Rather like a wooden Dutch } \\
\text { doll,» whispered Jane. }\end{array}$ & $\begin{array}{l}\text { И вот ребята увидели, что их мама } \\
\text { выходит из гостиной, а незнакомка } \\
\text { идёт за ней. Сверху были видны её } \\
\text { гладкие, блестящие чёрные волосы. «Как у } \\
\text { деревянной куклы», - шепнула Джейн. }\end{array}$ \\
\hline \multicolumn{2}{|c|}{ ПОВЕСТВОВАНИЕ ОТ ПЕРВОГО ЛИЦА } \\
\hline A. Burgess The Clockwork Orange & Пер. Е. Синельщикова \\
\hline $\begin{array}{l}\text { 7c. I could feel the knives in the old } \\
\text { moloko starting to prick, and now } \\
\text { I was ready for a bit of twenty-to-one. So } \\
\text { I yelped: 'Out out out out!' like a doggie, } \\
\text { and then I cracked this veck who was } \\
\text { sitting next to me [...]. }\end{array}$ & $\begin{array}{l}\text { Я чувствую, как скрытые в молоке иголки } \\
\text { начинают покалывать где-то внизу } \\
\text { в штанах. Вскакиваю и ору: «Камон, } \\
\text { камон, камон!» Потом, сам не знаю зачем, } \\
\text { двигаю в ухо выпавшему в осадок мэну } \\
\text { рядом [...]. }\end{array}$ \\
\hline
\end{tabular}

${ }^{12}$ Т.В. Пентковская, А.В. Уржа, Переводческие стратегии в древних и современных текстах: настоящее историческое, «Славистика (Београд)» 2013, № XVII, c. 174. 
В этих и подобных многочисленных фрагментах события представлены сквозь призму восприятия одного из их участников. Выбор форм настоящего времени при переводе на русский язык усиливает эффект вовлечения читателя в описываемое происходящее. Любопытно, что формам презенса нередко сопутствуют дополнительные дейктики, введенные в русский текст (см. примеры 7b и 7c).

Однако отмеченная нами закономерность не является универсальной. В сопоставлении с версиями переводчиков, выбравших формы настоящего времени для интерпретации оригинальных фрагментов, можно рассмотреть конкурирующие варианты, в которых использованы формы прошедшего времени, например:

\begin{tabular}{|c|c|c|}
\hline \multicolumn{3}{|c|}{ Марк Твен Приключения Тома Сойера } \\
\hline $\begin{array}{l}\text { Mark Twain The } \\
\text { Adventures of Tom } \\
\text { Sawyer }\end{array}$ & Пер. К. Чуковского & Пер. Н. Дарузес \\
\hline $\begin{array}{l}\text { 8. And now at this } \\
\text { moment, when hope } \\
\text { was dead, Tom Sawyer } \\
\text { came forward with } \\
\text { nine yellow tickets, nine } \\
\text { red tickets, and ten blue } \\
\text { ones, and demanded } \\
\text { a Bible. This was } \\
\text { a thunderbolt out of } \\
\text { a clear sky. }\end{array}$ & $\begin{array}{l}\text { И вот в ту минуту, когда } \\
\text { его надежда угасла, } \\
\text { выступает вперед Том } \\
\text { Сойер и предъявляет } \\
\text { целую кучу билетиков: } \\
\text { девять желтых, девять } \\
\text { красных и десять синих, } \\
\text { и требует себе в награду } \\
\text { библию! Это был удар } \\
\text { грома среди ясного неба. } \\
\end{array}$ & $\begin{array}{l}\text { И в ту самую минуту, когда } \\
\text { всякая надежда покинула } \\
\text { его, вперед выступил Том } \\
\text { Сойер с девятью желтыми } \\
\text { билетиками, девятью } \\
\text { красными и десятью синими } \\
\text { и потребовал себе Библию. } \\
\text { Это был гром среди ясного } \\
\text { неба. }\end{array}$ \\
\hline
\end{tabular}

Наличие конкурирующих переводов с формами настоящего и прошедшего нарративного времени показывает, что такие решения представляют индивидуальную инициативу переводчиков, нередко - элемент их последовательной стратегии. Эта инициатива опирается и на понимание переводчиком авторских приемов, которые он стремится акцентировать, и на развитую нарративную традицию использования русских презенсных форм в повествовании.

Итак, поведение эгоцентриков в изученных русских переводах англоязычных нарративов определяется действием группы семантических, грамматических и стилистических факторов:

- в первую очередь, это особенности перспективы оригинального текста, наличие в нем фрагментов, описывающих непосредственное наблюдение событий, эпизодов, охваченных 
внутренней фокализацией. Представление колоритных событий в контексте восприятия может сопровождаться при переводе появлением дополнительных «приближающих» пространственных или временных дейктиков, форм настоящего исторического;

- во-вторых, это специфика языковой системы, позволяющей русским переводчикам использовать формы презенса для передачи англоязычных конструкций с согласованием времен и оборотами типа Complex Object, заменять номинации типа 'this/that morning' на 'сегодня утром';

- в-третьих, это влияние русской нарративной традиции, охватывающей не одно столетие активного использования форм настоящего исторического в качестве средства выдвижения наиболее колоритных событий повествования, широко использующей дейктики как маркеры субъективизации;

- в-четвертых, это применение индивидуальных переводческих стратегий, осознанно ориентированных на акцентирование авторских приемов.

Каждый из перечисленных факторов может сыграть особую роль при формировании конкретного текста - вот почему в итоге перед нашими глазами предстает целая палитра переводческих решений.

Как показывают результаты нашего исследования, в рамках нарративного режима (и в перволичном, и в третьеличном изложении) дейктический центр повествования в русских переводах часто дополнительно приближается к читателю. Эта закономерность является ощутимой, но не тотальной: конкурирующие переводы могут использовать формы прошедшего времени и не добавлять дейктические элементы - это зависит от решения переводчика. При этом явления дистанцирования (изъятия дейктиков) в изученных материалах единичны и маргинальны, замены форм презенса на прошедшее время не обнаружены. В диалогах героев, имитирующих речевой режим, дейктический центр при добавлении дейктиков не приближается, а просто актуализируется. Локализация дейктического центра нарратива при переводе - сложный, многофакторный процесс, сопрягающий языковые закономерности и стилистические традиции, особенности авторского текста и переводческой стратегии. 


\section{ЛОКАЛИЗАЦИЯ ДЕИКТИЧЕСКОГО ЦЕНТРА...}

\section{REFERENCES}

Apresyan, Yuriy. Izbrannyye trudy. Integral'noye opisaniye yazyka $i$ sistemnaya leksikografiya. Vol. 2, Moskva: Yazyki russkoy kul'tury, 1995 [Апресян, Юрий. Избранные труды. Интегральное описание языка и системная лексикография. Т. 2, Москва: Языки русской культуры, 1995].

Bühler, Karl. Sprachtheorie. Die Darstellungsfunktion der Sprache, Jena: Gustav Fischer, 1934.

Goethals, Patrick, De Wilde, Julie. "Deictic Center Shifts in Literary Translation: the Spanish Translation of Nooteboom's Het Volgende Verhaal.” Meta, 2009, no. 54 (4): $770-794$.

Levinson, Stephen. Pragmatics, Cambridge: CUP, 1983.

Mason, Ian, Şerban, Adriana. "Deixis as an Interactive Feature in Literary Translations from Romanian into English.” Target, 2004, No. 15 (2): 269-294.

Paducheva, Yelena. Egotsentricheskiye yedinitsy yazyka. Moskva: Izdatel'skiy Dom YASK, 2019 [Падучева, Елена. Эгоцентрические единицы языка, Москва: Издательский Дом ЯСК, 2019].

Pentkovskaya, Tat'yana, Urzha, Anastasiya. "Perevodcheskiye strategii v drevnikh i sovremennykhtekstakh: nastoyashcheye istoricheskoye." Slavistika (Beograd), 2013, No. XVII: 173-180 [Пентковская, Татьяна, Уржа, Анастасия. "Переводческие стратегии в древних и современных текстах: настоящее историческое”. Славистика (Београд). 2013, № XVII: 173-180].

Royster James, Thompson Stith. Guide to Composition, Chicago: Scott, Foresman and Co., 1919.

Segal, Erwin. "Narrative comprehension and the role of Deictic Shift Theory." Duchan, Judith, and Bruder, Gail, and Hewitt, Lynne (eds.). Deixis in Narrative: a Cognitive Science Perspective. Hillsdale, New Jersey: Lawrence Erlbaum, 1995. 3-18.

Urzha, Anastasiya. "Pertseptivizatsiya kak element perevodcheskoy taktiki.” Gumanitarnyy vektor, 2014, no. 4 (40): 57-62. [Уржа, Анастасия. "Перцептивизация как элемент переводческой тактики.” Гуманитарный вектор. 2014, № 4 (40): 57-62]. 